\title{
An exploration of nurse experience in caring for end of life care client and family in critical care setting in Indonesian context
}

\author{
Alfia Safitri ${ }^{1 *}$, Yanny Trisyani ${ }^{2}$, Anastasia Anna Iskandar ${ }^{3}$ \\ ${ }^{1}$ Master of Nursing, Faculty of Nursing, Universitas Padjadjaran, Bandung, Indonesia \\ ${ }^{2,3}$ Faculty of Nursing, Universitas Padjadjaran, Bandung, Indonesia
}

Key Words:

Nurse's experience

Intensive care unit

End of life care

Critical care nursing

Received: 3 June 2017

Accepted: 6 June 2017

Published: 30 June 2017

\begin{abstract}
The need of society toward end-of-life care is increasing, especially for the client being cared for in the ICU setting, where the nursing role is critical in this context. Some studies have indicated that nurses often feel distressed in caring for those clients. Therefore, the nursing knowledge related to caring for the client in the end-of-life phase is important for improving the nurse's insights. This study employed a qualitative phenomenological approach to explore nurses' experience in providing end-of-life care to the clients and their families in the ICU setting. Seven participants have participated in this study. Data collection was undertaken through in-depth interviews and analyzed using the Colizzi approach. The study results have described this phenomenon on four themes: the life and death are God's secret; the dilemma between doing the best for the client and terminating life support; Supporting the clients and families; Reflecting on the experience. The results of this study can expand the nursing knowledge related to end-of-life care and have the potential to improve the quality of care services provided to the clients in the end-of-life phase.
\end{abstract}

(C) 2017 The Author(s). Published by TAF Publishing.

\section{INTRODUCTION}

Dying and death is a complex situation in critical care unit. Despite the utilization of advanced technology in critical care unit, the deaths' number is still increasing. Dying and death in critical care unit are related to the disease or injuries, a decision to refuse treatment due to the exhaustion of technological intervention, and the failure to respond to the medical treatment [1]. The exhaustion of intervention and treatment withdrawal cause redirection of care from curative to palliative care and end-of-life care in critical care unit [1].

The nurse is the primary caregiver beside the other medical staff who care for client and family at the end-of-life phase [2]. Nurses who had more experience demonstrated good attitude caring for the end-of-life clients and family [3]. Many studies identified that nurses have more experience while caring for the client at the end of life. Almost all of them expressed distress because of dying. In otherwise cases, nurses felt honored and meaningful because they could provide care to the client and family at the end of their living [4]. The nurses faced the difficulties of that situation while they imagine their own death and

\footnotetext{
${ }^{*}$ Corresponding author: Alfia Safitri

†Email: fiasafitri90@gmail.com
} 
family. They state that they must commit their responsibility by being with the client. At that time, nurse must pay attention to the bereaved family [5]. Although several studies found that nurse experiences frequently care for the clients and their families in end-of-life but limited in focus specifically on explaining how nurse experiences in ICU actually in the Indonesian context with cultural difference. Nurses perceived their experience affected by their belief.

The study on experience is most apropriate with a qualitative approach. The design will help gain more understanding about the phenomenon which is like human experience [6]. So, the aim of this study is to explore how nurses experience caring for client and family at the end-of-life in Intensive Care Unit, Private Hospital, Bandung, West Java, Indonesia.

\section{LITERATURE REVIEW}

End-of-life care is a treatment to help clients with the progressive and incurable disease until the client dies [7]. The awareness and effort in improving through end-of-life care are increasing in ICU along with high mortality. The high mortality is probably caused by illness or injury, decisions to discontinue treatment related to fatigue against technological use, and inadequate responses to treatment [2]. End-of-life care is influenced by nurse's experience. The nurse who has more experience has an extended view of decision-making regarding the end-of-life care. In otherwise case, the nurse with limited experience in ICU has low confidence [8]. Nurses get more end-of-life care skills through their practical experience in the ICU [9]. The end-of-life care based upon religious beliefs is one of the most important to nursing and other health care providers. Islam considers that death is part of one's spiritual life and everyone will experience it Bahramnezhad et al. [10]. Life and death are God's provisions.

According to Islamic views, human life is sacred and precious. God is the creator of a human being and the owner of life so that He is the one who will end that life through a natural death [11]. The death is inevitable and unpredictable so that nurses do their best in treating clients at the end-of-life phase [12]. Nurses continue the treatment because they believe that there is a miracle and possibly that can happen by God's provision [13]. During end-of-life care, nurses often experience discomfort such as dilemmas in care. Nurses provide psychosocial support to the clients and families by engaging in and facilitating family discussions in decision-making regarding client care at the end-of-life phase [14]. Nurses need to listen, understand, help the families in decision-making, and support family choices related to client care [15]. Families are an important component involved in the decision-making process. The nurse believes that the family has a strong bond with the client and certainly wants to provide comfort to the clients before death. Therefore, nurses follow family decisions and facilitate them [16]. Nurse cares for client and family at the end-of-life phases such as accompanying clients and families. The nurse expresses end-of-life care as accompanying the client and focusing on spiritual habit like praying in client's bedside [17].

Nurses expressed spiritual habits such as praying and encouraging families praying along clients' bedside [18]. The other habits during the process of dying according to Muslims are to support client's dignity like encouraging the family to guide shahadatine (saying Declaration of Faith), reading Qur'an around the client, keeping the body clean, closing the eyes, and putting the deceased feet towards the Qibla (Mecca) [13]. Nurse may consider to involve the religious leader role at the end-of-life phase. The religious leader provides religious guidance both by praying and providing emotional support to the client and family. The religious guidance can help families get an understanding of the meaning of life better 
so as to allow them more adaptation to death [19]. Nurses caring for clients and families at the end-of-life phase are required to mediate with physicians to ensure that clients receive care based on their needs and wants. It aims at getting clients peaceful dying and family can decide and accept best decisions related to continuing and discontinuing the treatment [20].

\section{METHOD}

This study is a phenomenological descriptive design to identify nurse's experience of caring for client and family at the end of life. Phenomenology is a science to explain a particular phenomenon such as human life experience [6]. The study focuses on exploring the essence or meaning of individual experiences and describing a detailed description of the experience [21]. Participants are recruited from ICU, Private Hospital, West Java, Indonesia. Seven nurses who have experience of more than two years in an Intensive care setting were collected by purposive sampling technique and participated in the study. There was the selection of participants from this technique who have rich information related to the phenomenon and can express their experience [22]. The study was approved by the Health Research Ethics Committee, Universitas Padjadjaran. After obtaining a study permission from the hospital, researcher selected participants from the nurse's data obtained from the head of nursing in ICU.

Potential participants were given information about the study and written informed consent after willingness to participate. Nurses shared their experiences during an indepth interview with audio tape recorded and transcribed verbatim. Interviews were held at a hospital specifically in the nursing room according to participants' preference. Interviews were conducted from February until March 2017, lasted 30 to 45 minutes. Data were analyzed using Colaizzy method comprising of seven steps [23]. Data collection ended when redundancy of themes had been obtained. Concepts of credibility, confirmability, auditability, and transferability were used to obtain the rigor and trustworthines of the study [22]. The researcher contacted and gave a full transcript with a summary of the emergent theme to participants after analysis. Two supervisors checked the study process. Researcher audited all the document of the study and explained the full description of the context adequately so readers could make the transferability.

\section{RESULTS}

Participants in this study are seven nurses who work in the ICU, Private Hospital in Bandung Indonesia. Four of them are female and three men with average age 29-41 years old. Their experience of practicing in ICU ranged from 2.5 to 12 years. All of the participants held a diploma. The experiences of a nurse during end-of-life care emerged in four themes: life and death are God's secret, the dilemma between giving the best care and discontinuing life support, support to the client and their loved ones, and reflecting their experience during the end-of-life care. These are described in more detail below.

\section{The life and Death are God's Secret}

Nurses experience that life and death are God's secret such as no one can predict God's provisions about the time of death even the client in ICU with poor prognosis. Participants point out that the caring in ICU is an effort, and then God will determine the outcome. Participants point out that no one could predict death, clients with poor prognosis treated in ICU are not necessarily dead in ICU. It can be seen from some of the participants' expressions below: 
"several times a client with no spontaneous breath can die in ICU or discharge, the doctor says go home..."(1)

Another participant stated the same:

"Hopely there is a miracle in the name of age; we do not know even though medically there is no hope roughly, so it laboured..."(2)

Nurses believe that there is a miracle from God by giving the critical client a chance beyond human capabilities. Therefore, nurses try to give the best to maintain the client's life as much as possible [13]. The life experience of nurses in caring for end-of-life clients perceived by participants such as the treatment in ICU is an effort, and then God will determine the outcome. It is in accordance with the expression of the participants below:

"The essence of treatment is determined by God..." (6)

Partcipant 7 stated the same with partcipant 6.

"We are ordinary people, God determines..." (7)

Someone who holds certain beliefs believes in God's provisions regarding healing, life, and death. A person needs to seek treatment related to his illness, and God will give a chance [24]. Participants point out that death can't be predicted; clients with poor prognosis treated in ICU are not necessarily dead because life and death are God's destiny. The life experience of nurses in caring for end-of-life clients perceived by participants such as the treatment in ICU is an effort, and then God will determine the outcome either by giving a healing or disobeying. Therefore, participants still try to provide the best care for the client.

\section{The Dilemma between Doing the Best Care for the Client and Terminating Life Sup- port}

The themes were obtained regarding the dilemma between providing the best and discontinuing life support. The family decides to continue life support while this can not help the client and adds to the suffering. Otherwise, the family state does not conform to resuscitation and to discontinuation of life support. At this situation, the nurse must facilitate the family's desire that differs from theirs. Nurses state that they are not comfortable to stop medicine if the client still breathes, although their family state Do Not Resuscitate (DNR). On the other hand, they must respect and follow the family's wishes. It can be seen from the participants' expressions below:

"If the client is in terminal phase... We sometimes face the counter...like yesterday there was a family who asked Do Not Rescuscitate but client was still breathing...we aren't comfortable to stop the medicine..."(3)

Family is one of the most important components in the decision-making process especially when deciding to DNR. Families have a strong bond with clients and certainly want to provide comfort to the clients before death. Nurses follow family decisions and facilitate them [16]. In otherwise case, participants stated that their experience is like they must continue the machine because of a family's desire not to stop it. They can't force the family to discontinue life support. It can be seen from the participants' expressions below:

"We're the medical professionals...it's impossible for us to force the family to switch off the machine, and go home; it is not possible. The decisions are in the hands of the family. We just follow them..."(6)

Nurses decide to continue the treatment that is not beneficial to the client due to family requests. The family has not accepted the client's condition and tries the maximum effort [25]. Nurses continue the life support because of the need to wait for family attendance and their decision, although doctor has decided that [26]. Sometimes participant 
gives advice to the family to stop life support because the client has a poor condition and minimal life expectancy if maintained. Participants' expressions can be seen below:

"...If the client is already in a poor condition... we support the family to stop their treatment, hopefully it's the best, the treatment is up ..." (5)

Nurses suggest the family not to continue resuscitation. They believe that client's death is the best choice for the client and family where the client's life expectancy is minimal if resuscitation continues. The nurses also revealed that continuing resuscitation increases the client's suffering $[27,28]$. Participants state that they face a dilemma between providing the best care and discontinuing life support while it differs from them. The family decides to continue life support while this can not help the client; on the contrary, adds to the client's suffering. Otherwise, the family state to do not rescucitate and to discontinue life support. Nurses must facilitate the family's desire because the family is one of the most important components and must be involved in client's care decisions.

\section{Support the Clients and Families}

There is experience of providing care to the clients at the end-of-life phase such as supporting the client and family. Participants reveal their experience of assisting families and clients at the end-of-life phase. Participants also facilitate families' presence and involve doctors and religious leader in the process of providing assistance. The life experience of the nurse in end-of-life care is like accompanying the client's family. Participants revealed motivating and calming the bereaved family. It can be seen from some of the participants' expressions below:

"We calm while stroking the back of his family...(3)"

The another participant stated the same, like the expression:

"Explain at that time not over-sad, later if the conditions deteriorate, sincerely accept it ..." (7)

The nurse accompanies the client's family at the end-of-life such as listening, giving a touch, and being near a grieving family $[14,28]$. The nurse also provides comfort and psychological support to the families who are physically and emotionally exhausted [29]. The experience in performing end-of-life care is expressed by the participant like accompanying the client by emphasizing the spiritual habit. It can bee seen from the participants' statements below:

"We guide as we can, play Qur'an digytal...every shift we pray for healing..."(2)

Participant 4 described the same expression with participant 2.

"Play Qur'an digytal...praying before and after the treatment...guide shahadatine..." (4)

In accordance with [18], nurses perform spiritual habits such as praying for the clients. Prayer has a spiritual value and provides peace and comfort to the client, as expressed by Bahramnezhad et al. [10]. Participants state their experience in end-of-life care like facilitating the family to accompany the client. It can be seen from some participants' statements below:

"If client is already near death, we ask the family to accompany the client to guide shahadatine...dhikr and read Holy Qur'an ..." (2)

The statement is also expressed by participant 3 .

"If suppose already deteriorated, we call the family for shahadatine, read holy Quran..." (3)

Nurses encourage the family to guide shahadatine and read the Quran around the client to give the peaceful deaths [13]. Participants involve the doctor and religious leader in providing spiritual guidance both by praying and providing emotional support when the client's condition deteriorates. There are some participants' statetements below: 
"Suppose the condition is already down...call the doctor, religious leader, all of the care providers have gathered ..." (2)

The same statement was expressed by Participant 7.

"Call the blue code team...then religious leader to guide shahadatine..." (7)

The participants' life experience in end-of-life care includes involving doctors and religious leader to discuss the decision to terminate the ventilator with families who fear that it will kill the client. It can be seen from participants' statetements below:

"If family wants to open ventilator, we call religous leader to discuss with family... "(1)

The other participant said the same:

"We suggest the family to discuss with a religious leader who will explain from a religious standpoint. Is it killing the client or not ..."(6)

Nurses mediate with physicians to ensure the clients and families receive the best care. It can also help the family to make the best decisions based on client's condition [20]. The life experience of the nurse in end-of-life care is like supporting the client's family by motivating them to be willing to accept the client's condition and death. Participants also revealed calming the bereaved family. Participants also accompany the client by emphasizing the spiritual habit such as playing digital Quran near the client, praying, guiding dhikr and shahadatine. Participants state their experience in end-of-life care is like engaging in and facilitating the family to accompany and to guide shahadatine the client, dhikr, and reading the Holy Quran near the client. Participants also involve the doctors and religious leader to accompany during the dying process or when the client's condition deteriorates. The religious leader prays and guides shahadatine along with the family.

\section{Reflecting on the Experience}

The theme of "reflecting on the experience" is expressed by participants such as preparing for their own death. Participants also reveal applying the certain values while caring for the client and family. Participants state that providing end-of-life care makes them try to improve themselves and their everyday work to face the unpredictable deaths. This can be seen from some of the participants' expressions below:

"Our life will be death, so we must improve ourselves, our work must be better than before..."

Participant 4 described the same expression with participant 2.

"Do everything better than yesterday, as a preparation for us... prepare that more and more..."

Nurses state that caring for end-of-life clients more often makes nurses evaluate their own lives and teach the meaning of life. Nurses are grateful for every thing they have and try to do their better work [4]. Participants also expressed that they prepare theirself to face death such as love themselves and family more. Here are the participants' expressions.

"We love ourself, to give more attention to our health and family actually... "(5)

Nurses revealed that providing the end-of-life care gives them a positive feeling in which they begin to be grateful and appreciate everything they have and love their family [29]. The experience of providing end-of-life care expressed by participants is related to applying the certain values such as giving more attention and communicating with the clients, despite the clients being unconscious. This can be seen from some of the participants' expressions below: 
"Care to his clients, give more attention to them... care them slowly, talk to them, giving excuses ..." (1)

Nurses provide the care to the clients with great tenderness and respect for the clients [18]. The theme of "self-reflection" is expressed by the participants such as preparing themselves for dying by trying to be better and loving themselves and family. Participants also reveal caring for clients by applying certain values such as give attention and communicating with the clients.

\section{DISCUSSION \& CONCLUSION}

The nurses' experience of caring for the client and family at the end-of-life is about life and death is God's secret. No one can predict God's provisions about the time of death. Therefore, participants still try to do the best for the clients. Every event in the world has a cause, and it can not be avoided according to God's provisions [10]. Death is a part of life that normally occurs and is inevitable [30]. Muslims believe that life and death are God's provisions or secrets.

Human life is sacred and precious according to the Islamic view. God is the creator and the owner of human life so that He is the one who will end that life through a natural death at a predetermined time [11]. Nurses believe that there is a miracle according to the God's provision beyond human prediction. Therefore, nurses need to maintain the client's life as much as possible. Participants believe they will do a sin if they stop the machine or end a person's life [13]. Nurses express their experience like having a dilemma between giving the best care and teminating the life support. The nurses must facilitate the family's desire to continue life support while this can not help the client. It will increase the suffering. Otherwise, nurses sometimes follow family's decision not to do the resuscitation and to continue life support. Nurses involve the family in making decisions in end-of-life care [14].

The family has a strong bond with the client and certainly wants to provide comfort to the clients [16]. The family has unrealistically high expectations that often can be observed in two aspects such as continuation and discontinuation of treatment. Family is optimist and decides to continue the treatment, although the client has a poor condition for a long time. In contrast, the family is willing to discontinue the treatment because it is not to help the client's condition otherwise postpone client's death. Both lead to a dilemma for nurses [13]. The other experiences are perceived by the participants such as supporting the clients and families. Participants reveal about accompanying the bereaved family. Nurses try to listen and give a touching [14]. Nurses also provide comfort by showing a compassion and empathy to the families who are physically and emotionally exhausted [29].

The nurses experience not only accompanying the family but also the clients such as playing the Qur'an digitally, dhikr, praying, and guiding shahadatine. Nurses express their religious habits such as praying at the client's bedside [18]. The spiritual support can also be given such as involving the religious leaders at the client's bedside [17]. Accompanying the client and family at the end-of-life according to participants involves facilitating the family presence. The client needs family presence and family wants to always be near the client. Participants attend the family when the client has deteriorated. Family guides, prays, and reads the Holy Qur'an. Nurses support and ensure the family presence [31, 32, $33,34]$. The nurses also facilitate the family and client to spend more time and say goodbye [20]. In support of peaceful deaths, nurses perform certain habits during the process of dying according to Muslim beliefs such as encouraging the family to guide shahadatine and 
reading the Qur'an [13]. Nurses reflect their experiences while the end-of-life care makes them improve themselves and work. The nurse reveals that the opportunity to care for the client in the end-of-life phase is a valuable opportunity and responsibility as a God-given, so they should be grateful for that. Therefore, nurses appreciate the clients and try to do their best. The nurses declare that God will also give a reward for performing their human duty [13]. The results of this study conclude that nurses need to provide the optimal care to help the clients and families. Nurses feel a dilemma related to continuing and stopping life support. Another thing is that nurses give the support to the dying clients and families in focusing on facilitating their spiritual needs either independently or involving the other health care providers like a doctor and religious leader. They provide the end-of-life care reflecting their experience by improving themselves and the work.

\section{RECOMMENDATIONS}

The results of this study have a potential to expand the nursing knowledge related to endof-life care as well as have the potential of improving the quality of care services provided to the clients in end-of-life phase. The further study is needed to get an understanding of the experience of family and their need in end-of-life care beside nurse's experience.

\section{ACKNOWLEDGMENT}

The authors would like to extend their gratitude to the Ministry of Finance of Indonesia through Education Fund Management Institution (LPDP) for their financial support under a contract number PRJ-1070/LPDP/2015.

\section{REFERENCES}

1. Vanderspank-Wright B, Fothergill-Bourbonnais F, Brajtman S, Gagnon P. Caring for patients and families at end of life: The experiences of nurses during withdrawal of life-sustaining treatment. Dynamics. 2011; 22(4): 31-35.

2. Perry AG, Potter PA. Buku ajar fundamental keperawatan: Konsep, proses, dan praktik. Jakarta, ID: EGC, 2005.

3. Wolf J. Exploring rituals in nursing. New York, NY: Springer Publishing Company, 2014.

4. Strang S, Henoch I, Danielson E, Browall M, Melin-Johansson C. Communication about existential issues with patients close to death—Nurses' reflections on content, process and meaning. Psycho-Oncology. 2014; 23(5): 562-568.

DOI: $10.1002 /$ pon.3456

5. Campbell M. Nurse to nurse: Perawatan paliatif. Jakarta, ID: Salemba Medika, 2013.

6. Streubert H, Carpenter D. Qualitative research in nursing. Philadelphia, PA: Wolters Kluwers, Lippincott Williams \& Wilkins, 2011.

7. Rosser M, Walsh H. Fundamentals of palliative care for student nurses. Oxford, UK: Willey Blackwell, 2014.

8. Powazki R, Walsh D, Cothren B, Rybicki L, Thomas S, Morgan G, Karius D, Davis MP, Shrotriya S. The care of the actively dying in an academic medical center: A survey of registered nurses' professional capability and comfort. American Journal of Hospice and Palliative Medicine. 2014; 31(6): 619-27. D0I: 10.1177/1049909113505194

9. Holms N, Milligan S, Kydd A. A study of the lived experiences of registered nurses who have provided end-of-life care within an intensive care unit. International Journal of Palliative Nursing. 2014; 20(11): 91-108.

DOI:10.12968/ijpn.2014.20.11.549

10. Bahramnezhad F, Cheraghi MA, Mehrdad N, Zendehdel K. View Of main religions of the world on: Don't attempt Resuscitation Order (DNR). International Journal of Medical Reviews. 2016; 3(1): 401-405. 
11. Abu-El-Noor Dr MK. End of Life-decisions: An Islamic perspective. Online Journal of Health Ethics. 2014; $10(1)$ : 4-10. DOI: $10.18785 /$ ojhe. 1001.04

12. Nicol J, Nyatanga B. Palliative and end of life care in nursing. Thousand Oaks, CA: Sage Publication, 2014.

13. Borhani F, Hosseini SH, Abbaszadeh A. Commitment to care: A qualitative study of intensive care nurses' perspectives of end-of-life care in an Islamic context. International Nursing Review. 2014; 61(1): 140-147. D0I: 10.1111/inr.12079

14. Kisvetrová H, Školoudík D, Joanovič E, Konečná J, Mikšová Z. Dying care interventions in the intensive care unit. Journal of Nursing Scholarship. 2016; 48(2): 139-146. D0I: 10.1111/jnu.12191

15. Arbour RB, Wiegand DL. Self-described nursing roles experienced during care of dying patients and their families: A phenomenological study. Intensive and Critical Care Nursing. 2014; 30(4): 211-218. D0I: 10.1016/j.iccn.2013.12.002

16. Bahramnezhad F, Cheraghi MA, Mehrdad N. Iranian nurses' perspective on non-resuscitation: Content analysis. International Journal of Medical Research \& Health Sciences. 2016; 5(6): 136-145.

17. Swinton M, Giacomini M, Toledo F, Rose T, Hand-Breckenridge T, Boyle A, Woods A, Clarke F, Shears M, Sheppard R, Cook D. Experiences and expressions of spirituality at the end of life in the intensive care unit. American Journal of Respiratory and Critical Care Medicine. 2017; 195(2): 198-204. DOI: 10.1164/rccm.201606-11020C

18. Periyakoil VS, Stevens M, Kraemer H. Multicultural long term care nurses' perceptions of factors influencing patient dignity at the end of life. Journal of the American Geriatrics Society. 2013; 61(3): 440-446. D0I: 10.1111/jgs.12145

19. Macêdo EL, de Andrade LD, Martins SR, de Souza Medeiros MV, de Brito DT, Nagashima AM, Agra G, Pinto MB, Nogueira MF, De Sousa AT, Cerqueira AC. Influence of religious leaders in the health-disease process. International Archives of Medicine. 2017; 10 (1): 1-13. DOI: 10.3823/2289

20. Becker CA, Wright G, Schmit K. Perceptions of dying well and distressing death by acute care nurses. Applied Nursing Research. 2017; 33(2): 149-154. DOI: 10.1016/j.apnr.2016.11.006

21. Creswell JW. Research design: Qualitative, quantitative and mixed methods approaches. Thousand Oaks, CA: Sage Publications, 2014.

22. Polit DF, Beck CT. Essentials of nursing research: Appraising evidence for nursing practice. Philadelphia, PA: Lippincot Williams \& Wilkins, 2010.

23. Colaizzi P. Reflection and research in psychology: A phenomenological study of learning. Iowa, IA: Kendall/Hunt Publishing Company, 1973.

24. Werth Jr JL, Blevins D. Decision making near the end of life: Issues, developments, and future directions. Abingdon, UK: Routledge Taylor \& Francis, 2008.

25. Anstey MH, Adams JL, McGlynn EA. Perceptions of the appropriateness of care in California adult intensive care units. Critical Care. 2015; 19(1): 51-55. D0I: 10.1186/s13054-015-0777-0

26. Ranse K, Yates P, Coyer F. End-of-life care in the intensive care setting: A descriptive exploratory qualitative study of nurses' beliefs and practices. Australian Critical Care. 2012; 25(1): 4-12 D0I: 10.1016/j.aucc.2011.04.004

27. Assarroudi A, Nabavi FH, Ebadi A, Esmaily H. Do-not-resuscitate order: The experiences of Iranian cardiopulmonary resuscitation team members. Indian Journal of Palliative Care. 2017; 23(1): 88-92.

28. Ibrahim S, Manaf MRA, Aizuddin AN. Managed care: What do private general practitioners (GPs) think? International Journal of Health and Medical Sciences, 2015; 1(1): 8-16. D0I: 10.20469/ijhms.30002

29. Adams JA, Anderson RA, Docherty SL, Tulsky JA, Steinhauser KE, Bailey DE. Nursing strategies to support family members of ICU patients at high risk of dying heart \& lung. The Journal of Acute and Critical Care. 2014; 43(5): 406-415. D0I: 10.1016/j.hrtlng.2014.02.001

30. Zheng RS, Guo QH, Dong FQ, Owens RG. Chinese oncology nurses' experience on caring for dying patients who are on their final days: A qualitative study. International Journal of Nursing Studies. 2015; 52(1): 288-296.

DOI: $10.1016 /$ j.ijnurstu.2014.09.009 
31. Peterson J, Johnson M, Halvorsen B, Apmann L, Chang PC, Kershek S, Scherr C, Ogi M, Pincon D. Where do nurses go for help? A qualitative study of coping with death and dying. International Journal of Palliative Nursing. 2010; 16(9): 16-21. DOI: 10.12968/ijpn.2010.16.9.78636

32. Suksathan W, Chotisiri SL, Vorasiha P. Undergraduate students perception towards the 1st clinical experiences in fundamental nursing skills practicum: A qualitative study. International Journal of Health and Medical Sciences. 2016; 2(3): 64-67.

33. Fridh I, Forsberg A, Bergbom I. Doing one's utmost: Nurses' descriptions of caring for dying patients in an intensive care environment. Intensive and Critical Care Nursing. 2009; 25(5): 233-241. D0I: 10.1016/j.iccn.2009.06.007

34. Balcom S. Surviving and thriving in intensive care: Preparing new nurses. International Journal of Health and Medical Sciences, 2015; 3(1): 48-50. DOI: 10.20469/ijhms.30001-3

— This article does not have any appendix. - 